\title{
Epistemic Struggles in Addiction Therapeutic Community Meetings ${ }^{1}$
}

\author{
Marco Pino $^{2}$
}

\begin{abstract}
In this study I analyse Therapeutic Community (TC) group meetings for persons with drug addiction problems. Using the method of Conversation Analysis, I specifically focus on practices of knowledge management and sharing between the educators and clients of a TC in Italy. As part of their institutional remit, the educators encourage the clients to report information on their activities and to disclose aspects of their inner experience. This can lead to epistemic struggles, in which the clients resist providing information and the educators seek to overcome such resistance by making claims of pre-existing knowledge about the clients' experience. After describing the design and sequential positioning of such claims, I argue that their use is functional to manage one of the dilemmas that characterise the educators' professional practice.
\end{abstract}

\section{Keywords}

Conversation analysis, Epistemics, Knowledge management, Substance abuse treatment centers, Therapeutic community

\footnotetext{
1 Preprint copy of: Pino, M. (2014) Epistemic Struggles in Addiction Therapeutic Community Meetings. In A. Zuczkowski, R. Bongelli, I. Riccioni and C. Canestrari (Eds.), Communicating certainty and uncertainty in medical, supportive and scientific contexts, pp. 201-221. John Benjamins.

${ }^{2}$ Correspondence to: Corresponding author: Marco Pino - Sue Ryder Centre for the Study of Supportive, Palliative and End of Life Care - The University of Nottingham, School of Health Sciences, Queen's Medical Centre, Nottingham, NG 7 2HA, UK - Email: marco.pino75@gmail.com
} 
Therapeutic Communities (TCs) are settings for the rehabilitation and support of people with mental health and addiction problems. Some of their distinctive features are: (a) a location removed from a hospital, into a 'normal' house; (b) intensive staff input with individual treatment programmes; (c) expectation of client involvement in domestic activities; (d) access to opportunities of social involvement in the area where the house is located (Macpherson, Edwards, Chilvers, David, and Elliott 2009). Another distinctive mark of TCs is the value attached to group meetings, which are carried out on a weekly basis with several purposes. The Service Standards for Addiction Therapeutic Communities mandate that "discussions take place from which community members learn and gain understanding from everyday living" (Shah, and Paget 2006, 16). In this article I analyse such discussions in the context of some group meetings that I recorded in a larger project in a semi-residential TC in Italy. My aim is to describe practices of knowledge sharing and management in the TC meetings. After establishing the central role of knowledge management in the interactional tensions that arise in the meetings (what I refer to as epistemic struggles), I focus on a set of practices by which the TC professionals (called educators) pursue information about the clients' activities and experiences. Specifically, I focus on how these practices index different degrees of pre-existing access to the clients' experiences. Finally, I discuss their implications for the interaction and the institutional setting of the TC.

\section{Therapeutic Community Monday Meetings}

The TC where I carried out my research provides rehabilitation and support for people with drug addiction problems. It is located in a major Italian city, and is managed by a private organization in collaboration with the local public health service. Clients do not pay to receive treatment. The TC is not residential: clients attend the TC from Monday to Friday, from 8.00 a.m. to 5.00 p.m.

The meetings analysed in this study are carried out at the TC every Monday. The meetings are attended by two TC professionals (called educators) and the TC client members. In the Monday meetings the clients are expected to report their activities in the course of the weekend (spent outside the TC). The reporting activity is actively sustained by TC educators' interventions that have two main functions: (a) to provide for an articulated report of the weekend; (b) to isolate in the report one or more issues or problems that can be subsequently scrutinized and assessed.

In the following example, a client called Carlo starts his report with a reference to an individual program that the clients write up every Friday, in which they commit to engage in specific activities in the course of the 
Pino - Epistemic Struggles in Addiction Therapeutic Community Meetings

incipient weekend. Among the functions of the Monday meetings is to verify whether the clients have followed their individual program. Carlo starts his report by claiming that he has not abided by the program. Marta and Annamaria are two TC educators. Other clients are present at the meeting but they do not intervene in this extract (information on the data and method for this study are provided in the next section).

\section{Extract 1 (INT4:15)}

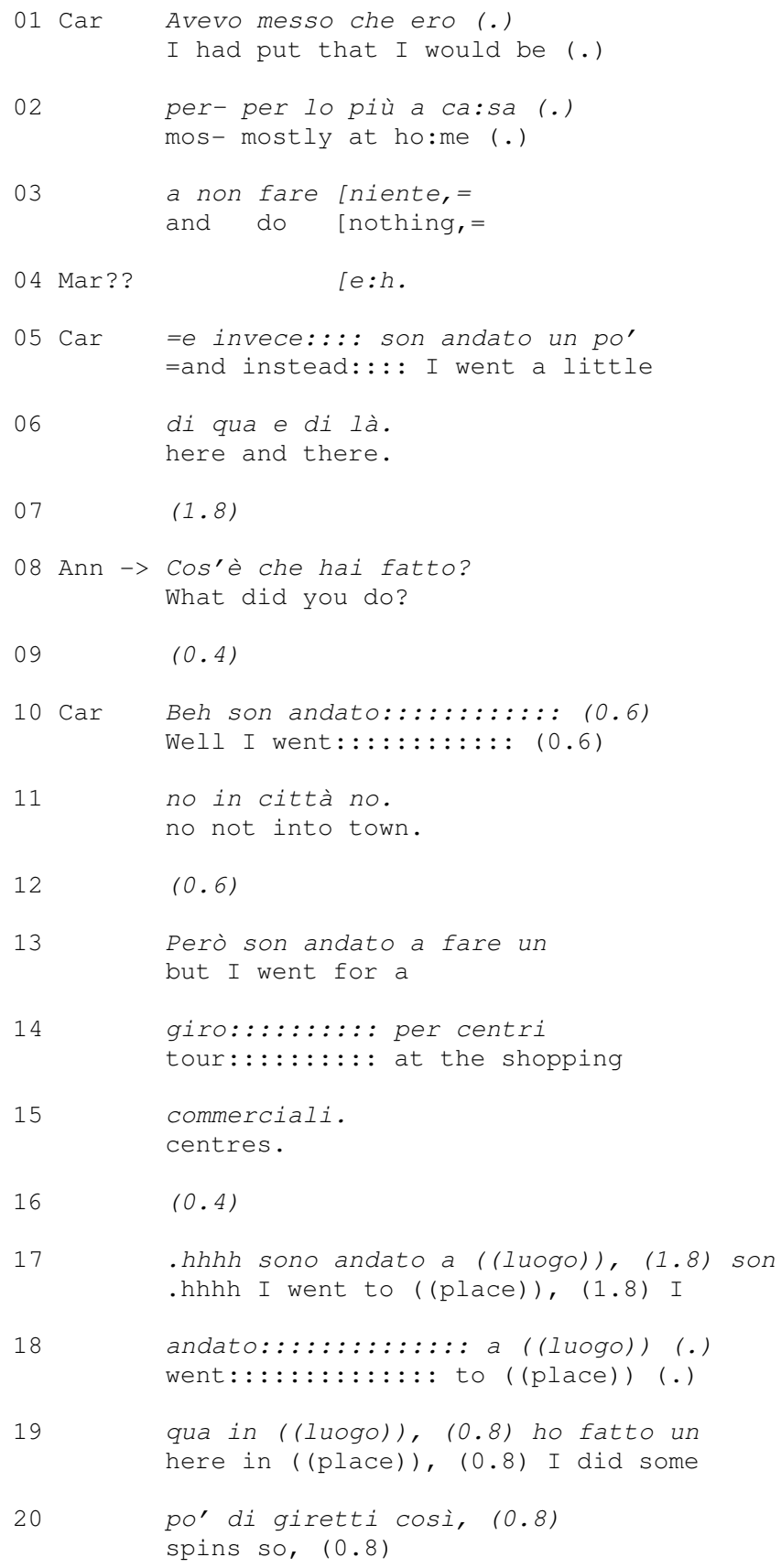




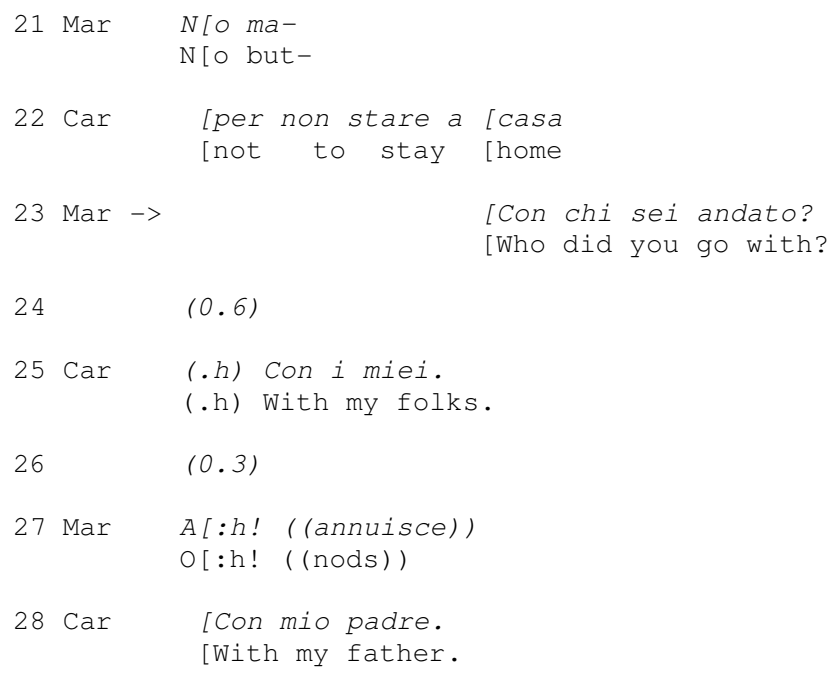

In lines 1-3, Carlo produces the first turn constructional unit of an announcement, stating that he had written in his program that he would stay at home in the weekend. A speaker (possibly Marta) overlaps the last word of the unit with a continuer (line 4). Carlo completes the announcement in lines 5-6 with a second unit. A gap ensues in which Carlo might be expected to detail his announcement by giving a full report. As he does not do so, Annamaria issues an inquiry (line 8). In lines 10-20 Carlo reports that he went to visit some shopping centres, an activity that he eventually glosses as 'doing some spins' (lines 19-20). In light of the fact that the exchange takes place in a TC meeting, in which the client's report is likely to be inspected in order to understand whether he engaged in possibly dangerous or antitherapeutic behaviours (such as going to places where he might meet people who could sell him drugs), Carlo's detailing of what he did makes available the picture of a rather innocent and harmless type of activity (Drew 1998), thus downgrading the possible seriousness of his transgression.

This information is treated as insufficient by Marta (another educator) who produces a second inquiry (line 23) focusing not on where Carlo went but with whom. Carlo's response again provides information that is compatible with the picture of rather innocent and non-harmful activities: he went out with his parents (information which is revised in line 28, where Carlo mentions his father). Marta's "ah" token in line 27 indexes that she has registered the provision of the required information (Heritage 1984), which she reflexively treats as sufficient and adequate for all practical purposes. In the continuation of the exchange (not shown here), after Annamaria issues a further inquiry which momentarily shifts the focus of the discussion, Marta refers back to the information provided in lines 25 and 28 in order to provide a positive evaluation of Carlo's conduct.

The educators' inquiries provide for the clients to give information that can help them to evaluate their conduct in the weekend. Two related 
aspects of the educators' inquiries are involved in preparing the ground for an evaluation. First, through their inquiries the educators display an unknowing epistemic position (Heritage 2012) and thus provide for the clients to fill their gap of knowledge regarding their activities in the weekend. Second, the inquiries are selective with respect to the type of information that can be treated as a relevant requirement to issue an evaluation. For instance, Marta's inquiry in line 23 shifts the focus away from the issue of 'where' Carlo went to the issue of 'with whom' he went out.

Another implication stems from the fact that information is not neutral. For instance, "pubs" and "shopping centres" as possible responses to the inquiry in line 8 are likely to bear different consequences for the evaluation of Carlo's conduct. The same can be said for "friends" and "parents" as possible responses to the inquiry in line 23 . What the client reports has consequences for how his conduct will be evaluated. Thus, there are stakes involved in the management of information for both the TC educators and client members. The educators depend on the clients to provide reports that are sufficiently detailed and relevant in order to appraise their conduct. The clients are likely to be alert to the fact that what they say can be used to evaluate them (this orientation is embodied in Carlo's initial announcement in extract 1 , where he immediately characterises his conduct as contradicting his earlier commitments).

Whereas the client in extract 1 cooperates by providing the required information, interactional tensions commonly arise between the educators and the client members in this phase. In this article I focus on one source of such tensions: the displayed unwillingness to provide the information required by the educators. In such cases, information management can become an object of struggle. In the following sections I analyse an instance of this type of epistemic struggle. After showing how a client manages to withhold information, I analyse three practices that the educators employ to circumvent his resistance. I intend my article to contribute to two fields. First, I contribute to the study of TC meetings by arguing that some of the tensions that arise in them can be usefully conceptualised as epistemic struggles. Second, I contribute to the study of epistemics in social interaction (Heritage 2012) by analysing how epistemic rights and obligations can be managed in a specific type of institutional activity.

\section{Data}

Data for this article come from 8 meetings (4 audio-recorded; 4 video-recorded) that I collected in the context of an ethnographic study carried out in the addiction TC. The participants granted permission to publish the data. I transcribed the recordings by employing the technique 
commonly used in Conversation Analysis (CA), and originally devised by Gail Jefferson, which allows to capture several aspects of speech production, such as temporality (overlapping speech and silences), intonation, emphasis and others (for an overview, see Schegloff 2007). The transcripts in this article are presented in two lines: original Italian, and English idiomatic translation.

\section{Method}

The method for this study is Conversation Analysis (CA). CA is an approach for the study of how people accomplish social activities through talk (for an overview, see Sidnell 2010). In this article, I specifically build on CA studies of epistemics, conceived as "the study of the expression of and roles played by knowledge and knowledge claims in interaction" (Drew 2012). Heritage (2012) demonstrates that the distribution of knowledge between participants is a central resource in the organisation of conduct in social interaction. Specifically, he shows that the relative distribution of knowledge between participants can be used as a warrant for the initiation and closure of sequences of action whose main interactional purpose is the exchange of information. For instance, the display of an unknowing epistemic position by one of the parties can work as a warrant for the initiation of a sequence, which is brought to closure when the epistemic imbalance between the parties has been equalised for all practical purposes.

My study also builds on CA literature on preference organisation, conceived as the organisation of practices that promote social affiliation in interaction. When alternative actions are available to a participant - one that promotes affiliation and one that promotes disaffiliation - the alternative that promotes disaffiliation tends to be withheld with respect to points in interaction where it might otherwise be relevantly performed, and it is also marked by specific compositional features (such as the embedding of accounts, mitigations, excuses, and others). In this article I draw specifically on studies of the preference organisation of sequence initiating actions (Robinson, and Bolden 2010; Schegloff 2007).

In my analyses I focus on phases in the Monday meetings in which the educators provide for the clients to report their weekend activities. In this sequential environment, the educators mobilise the clients' reports by undertaking an unknowing epistemic position (Heritage 2012). Such displays vary in the extent to which they exhibit the educators' lack of knowledge or, alternatively, some pre-existing knowledge regarding the matters at hand (whose degree of certainty can be downgraded or upgraded). I am specifically concerned with how different displays of knowledge reflect different concerns and bear different interactional implications for the activity. 


\section{Pursuing information on a client's experience}

In what follows I analyse an episode taken from a single, audiorecorded meeting held at the TC. I have selected this particular episode because it permits illustration of a range of practices involved in dealing with a client's reluctance to provide information on his weekend. As I will make clear in a moment, the task of obtaining information is further complicated by the educators' focus on the client's inner, emotional experience (i.e. how he felt in the course of the weekend) and not on more publicly available events (i.e. what he did). The client's name is Samuele. Two educators (Annamaria and Marzio) and two other clients (Lidia and Diana) take part in the meeting. The clients are between 19 and 22 years old. All names used in this article are pseudonyms. In order to have a sense of the general focus of discussion, let us consider the following extract.

Extract $2(\operatorname{Pg} 3 \mathrm{~B}: 1)$

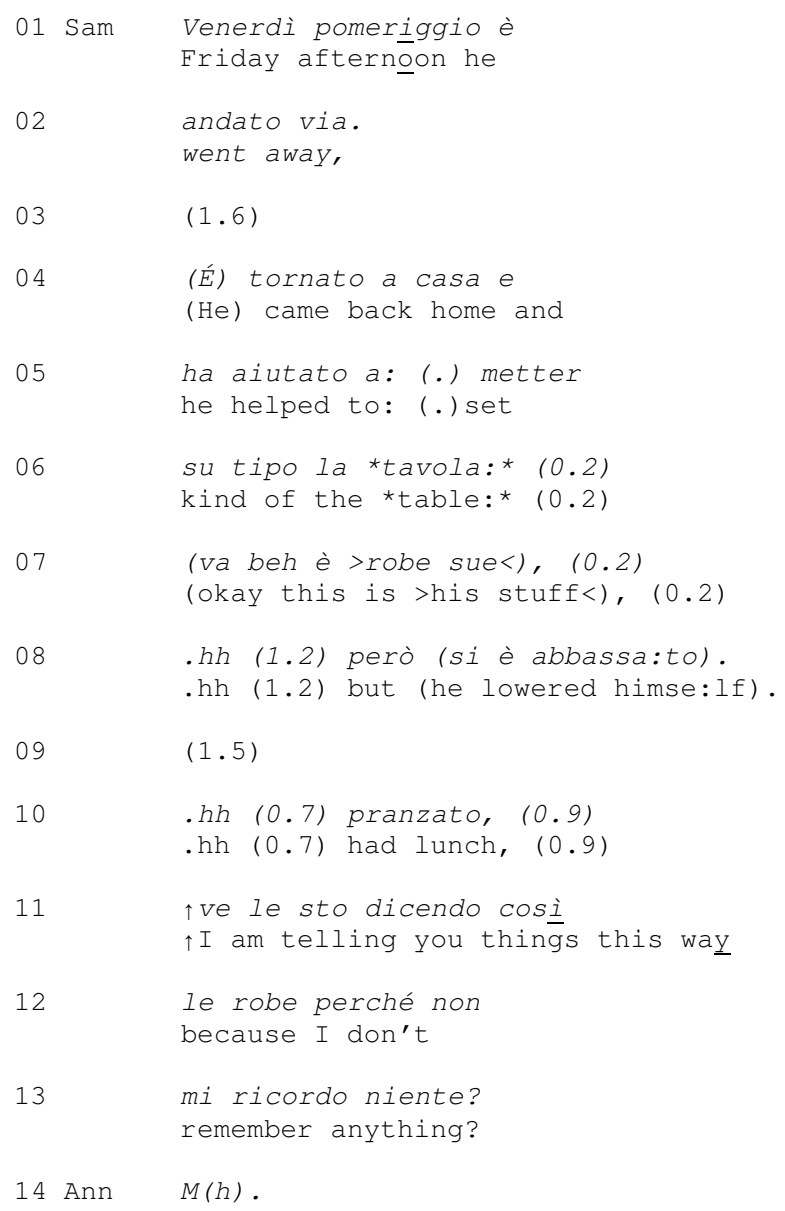




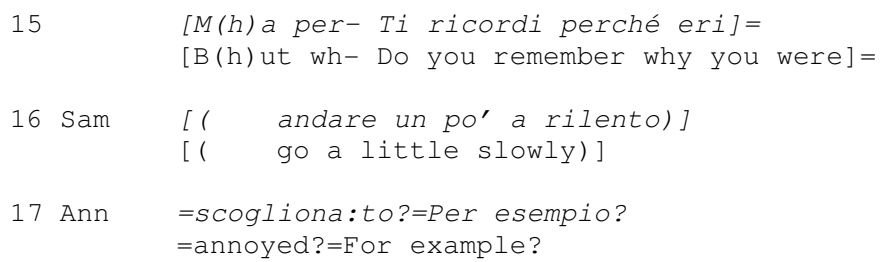

Across lines 1-8 Samuele references events involving his father. Three aspects are worth noting. First, Samuele provides a factual description of events that occurred in the previous days (his father went away, then he came back). Second, Samuele's talk is not self-oriented, but references a third person (his father). Third, the idiomatic "he lowered himself" seems to convey a possible complaint (Drew, and Holt 1988), which is made available for the recipients to take up (Mandelbaum 1991/1992). Following a lack of uptake (line 9), Samuele resumes his factual report (line 10) and then he interrupts it to produce a meta-comment (lines 11-13). In accordance with what Sacks (1987) described as a preference for contiguity, Annamaria (an educator) first addresses Samuele's meta-comment with a laughter token (line 14). Annamaria then produces an inquiry (lines 15, 17), which shares the two properties exhibited by the educators' inquiries in extract 1 . First, by producing a first pair part action that indexes an unknowing epistemic position, Annamaria makes relevant for Samuele to produce a second pair part that provides information to close the knowledge gap between them. Second, the inquiry is selective with respect to the type of information that the educator treats as relevant in the present context. By referring to an earlier comment by Samuele on his being "annoyed" on Saturday morning (not shown here), Annamaria focuses on his inner emotional experience. This focus stands in contrast with the quality of Samuele's description which focused on the facts, instead of his own inner experience, and was not self-oriented.

Annamaria's focus on Samuele's inner experience adds a layer of complexity to the interaction, compared to the exchange in extract 1 . As a matter of fact, whereas information about external events can be shared by participants to an interaction, information about one's own internal experience is ordinarily treated as something that is owned by the person (Heritage 2011; Peräkylä, and Silverman 1991). Venturing in the domain of the other's experience is, hence, a delicate enterprise and requires the collaboration of the person who owns the experience. Whereas the client in extract 1 can be normatively expected to provide information on his activities in the world (i.e. what he did) insofar as they are treated as relevant for the business at hand (e.g., assessing whether the client abided by the TC rules in the course of the weekend), providing for a client to disclose his internal experience (i.e. what one felt) is a different matter.

Annamaria's inquiry produces a turning point in the meeting; from this moment, the progressivity of the activity is made contingent on 
Pino - Epistemic Struggles in Addiction Therapeutic Community Meetings

Samuele's willingness to describe not the sheer facts in which he was involved, but what he experienced.

\section{Client's withholding of information}

Samuele employs several practices to withhold information about his inner experience in the course of the weekend. In this section I consider three of them.

Withholding talk

Extract 3 (Pg3B:16)

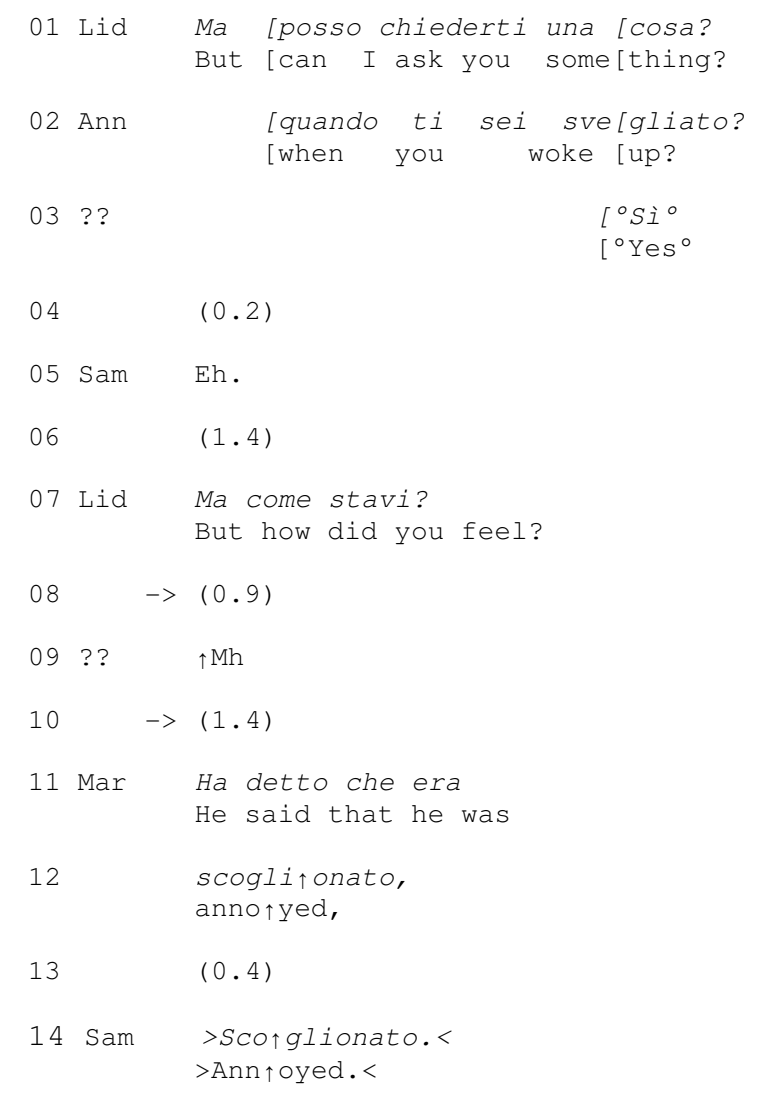

Extract 3 is a direct continuation of extract 2. Following Annamaria's inquiry, Lidia (one of the clients) produces a pre-question (Schegloff 2007) (line 1). Given that this is a first pair part and that it is produced after another first pair part has already been issued by Annamaria (who extends it in overlap in line 2), Lidia's turn competes with Annamaria's to become sequentially implicative and, hence, to constrain Samuele's response (Schegloff 2000). Samuele's response in line 5 is 
clearly addressed to Lidia's pre-question, in relation to which it constitutes a go-ahead response (Schegloff 2007). Following this, Lidia produces an inquiry which has a larger focus than Annamaria's earlier inquiry, insofar as it provides for Samuele to tell how he felt in general and not to account for a specific affective state (such as being annoyed). Nevertheless, this inquiry shares with Annamaria's inquiry the focus on Samuele's inner experience. Across lines 8 and 10 Samuele withholds talk that could answer Lidia's inquiry (the "mh" token in line 9 does not belong to him insofar as it is uttered by a non-identified female voice). Following Samuele's lack of uptake, Marzio (an educator) answers Lidia's inquiry on Samuele's behalf by citing the client's earlier reference to 'being annoyed'. Marzio's answer also constitutes a B-event statement or "my side" telling, that is, a claim made into Samuele's experiential domain (Pomerantz 1980). This type of statement has been described in earlier studies as making relevant a responsive action that makes available information from the epistemic domain in which the claim is being made (Heritage 2012b). In the case at hand, the sense of a claim which is being produced as a solicitation to talk is further conveyed by the slightly rising intonation at the end of Marzio's turn (line 12). Samuele eventually responds to the solicitation by repeating, and hence confirming, Marzio's formulation of his affective state ("annoyed"; Heritage and Raymond, 2012).

\section{Minimal responses}

Extract 3 provides an example of this practice. In line 14, Samuele confirms Marzio's formulation of his affective state through the repetitional ">Sco $\uparrow$ glionato. $<"$. This answer is minimal in two respects. First, it is minimal in a material way: it consists of single lexical item, whose extension is further reduced by the accelerated pace with which it is uttered (as if Samuele had designed it to occupy as little turn space as possible). Second, it is minimal in an informational way, insofar as it avoids providing anything more than what has already been provided by Marzio (Schegloff 2007). Let us turn to another example.

Extract $4(\mathrm{Pg} 3 \mathrm{~B}: 95)$

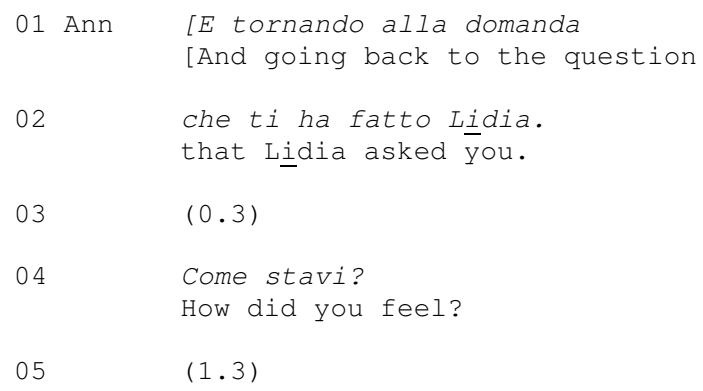




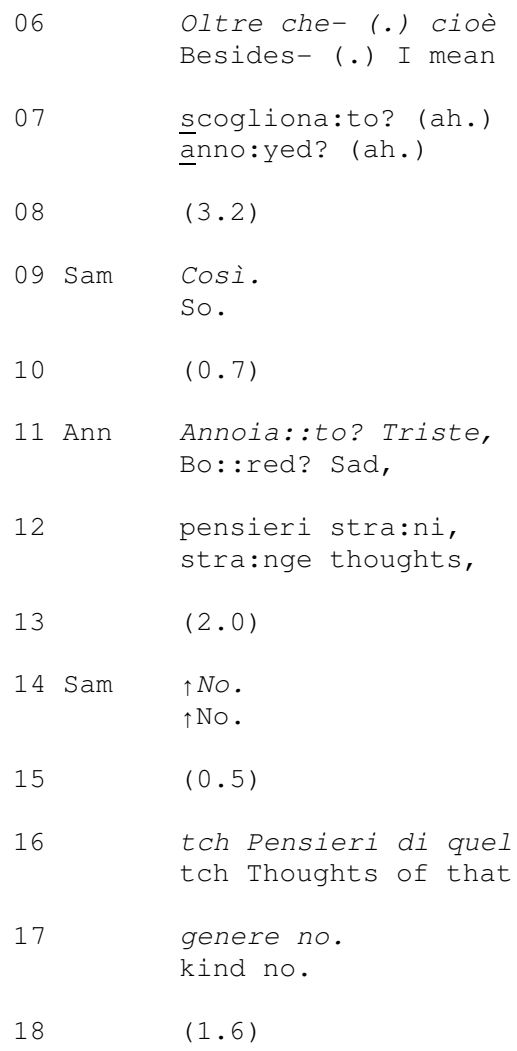

Annamaria's inquiry in lines 1-2 follows another segment of Samuele's factual description of his activities in the weekend, with respect to which it constitutes a topic shift and a further attempt to refocus the talk on the client's internal experience. The inquiry references (and renews the sequential implicativeness of) Lidia's earlier inquiry shown in extract 3, line 7. In lines 6-7 Annamaria establishes Samuele's earlier minimal response (extract 3, line 14) as insufficient. Following a gap, Samuele provides another minimal response. As in the earlier example, it is minimal both in the sense of being made of a single turn unit (specifically, a single lexical item) and of being non-informative. Following Annamaria's pursuit of a more informative response (in the form of an alternative question), and after a further gap, Samuele produces another minimal response, by denying that the latter of the options provided by Annamaria (the idiomatic "strange thoughts", which might refer to thinking about using drugs) applies to him. After a gap, he expands his turn by adding another turn unit. However, the response is still minimal insofar as it avoids providing more information on Samuele's inner experience.

\section{Factual descriptions}

Extract 5 (Pg3B: 353) 


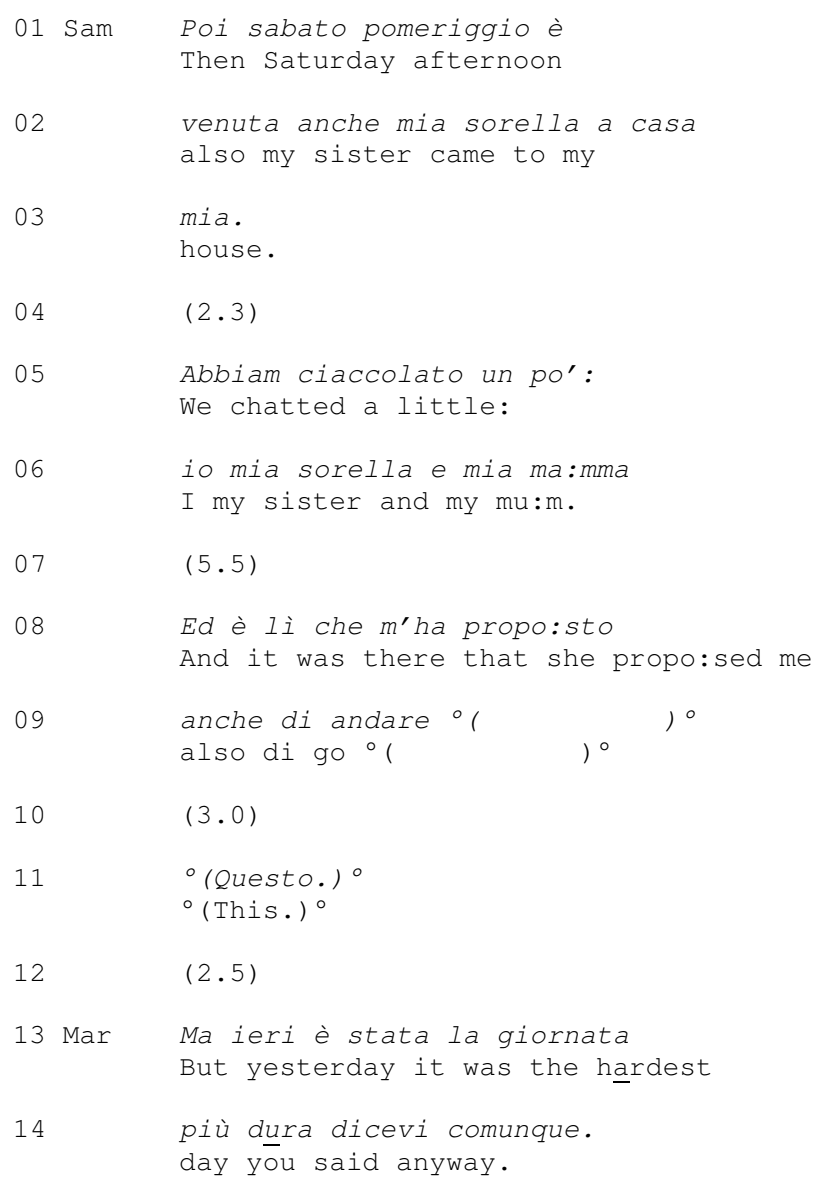

Recurrently across the meeting Samuele manages his own participation by returning to a factual description of the weekend events. In extract 5, Samuele's factual description of the events involving his mother and sister is followed by a "my side" telling by Marzio, who seeks to refocus the discussion on the client's internal experience.

\section{Summary}

Samuele employs different practices to resist his co-participants' solicitations to communicate aspects of his inner experience. The practices that I have illustrated all have implications for the epistemic work carried out in the meeting. By withholding talk, Samuele avoids providing information that can close the gap of knowledge indexed in his coparticipants inquiries. Minimal responses enable Samuele to satisfy the expectation of producing an at least pro forma responsive action to his coparticipants solicitations to talk, while at the same time conveying his unwillingness to provide more articulated and informative descriptions of his own experience. Factual descriptions also enable him to meet another 
expectation of the activity in progress - reporting on one's own activities in the course of the weekend - while avoiding providing information on one's own internal experience.

Samuele's resistance can jeopardize the activity in progress, insofar as the selective focus of the educators' solicitations on Samuele's inner experience have made its progressivity contingent on the provision of this type of information. It should be kept in mind that, in the overall organization of the meeting, clients' reports are followed by some type of responsive action (such as an assessment) in which the educators deliver their view of the facts that have been reported. In the case at hand, this stage in the interaction cannot be reached unless Samuele provides the required information, or unless the educators give up further attempts at pursuing that information.

\section{Educators' pursuit of information}

The TC educators employ different practices to deal with Samuele's resistance and to pursue information about his inner experience. These practices all mobilize informative sequences and they do so by virtue of indexing the educators' lack of knowledge of (and interest in) Samuele's state. Nevertheless, these practices are differently positioned on what Heritage describes as the epistemic gradient (Heritage, and Raymond 2012), insofar as they encode "different degrees of information gap and different levels of commitment to the candidate answer advanced by the questioner" (p. 180). In extract 1 (lines 8 and 23) the educators' inquiries index a complete lack of knowledge regarding the client's activities in the weekend. In the exchange with Samuele, the educators promote informative sequences by claiming varying degrees of pre-existing knowledge regarding his internal states. Different types of claims appear to be treated as nonequivalent. The educators first employ solicitations that index only generic or hypothetical knowledge about Samuele's state. However, following the client's non-cooperation, they produce solicitations that encode some preexisting knowledge of his internal experience in the weekend. In Heritage's terms, the educators gradually alter their epistemic stance and modify the slope of the epistemic gradient between themselves and the client from deep to shallow (Heritage 2012). The fact that such knowledge displays are deployed later in the meeting testifies to their dispreferred or socially devalued character (Schegloff 2007). It is arguable that the educators withhold displaying pre-existing knowledge of Samuele's state in order to provide for the preferred alternative of having the client communicate information on his inner state (Robinson and Bolden, 2010). The dispreferred nature of making claims about the client's experience is also reflected in the design of those claims. In what follows I consider three 
practices by which the educators pursue information on Samuele's inner experience in the weekend, which can be located on a continuum between the lower to the higher display of knowledge regarding his experience.

\section{Pursuing information from a relatively unknowing epistemic position}

Information about Samuele's inner experience is pursued across his displays of resistance in several ways, such as different question formats and candidate answers. Let us consider the alternative question in extract 4, lines 11-12. It addresses Samuele's displayed unwillingness to talk about his inner state by providing a set of alternatives among which he could choose (Koshik 2010). The question carries an implied claim of knowledge about Samuele's experience in general or hypothetical terms. Annamaria builds on prior knowledge about Samuele's experience in order to produce a list of possible answers in a recipient-designed way. Such knowledge grounds, for example, the possibility that Samuele might have had "strange thoughts". Nevertheless, no claim is made or conveyed about how precisely Samuele felt in the course of the weekend. The alternatives are simply offered as relevant possibilities, not as actual affective states that Samuele might have experienced. The question, hence, builds on general knowledge about Samuele, which is arguably available to anyone who has an established relationship with him in the TC (educators and clients). In this respect, it indexes a relatively unknowing epistemic position with regard to the matter under discussion.

Another instance is in extract 5, lines 13-14. This "my side" telling is deployed to promote a topic shift and a return to talk that references Samuele's inner experience, which it describes through the candidate formulation "hard". Through the evidential "you said", the claim is cautiously presented as grounded in what Samuele has made available earlier in the meeting. As in the case of the alternative question in extract 3, Marzio's statement displays a comparatively low degree of knowledge about Samuele's experience, insofar as its conveyed epistemic claim is limited to the surface of what Samuele has verbally made available in the meeting.

What these practices convey is the educators' interest in gaining more knowledge of Samuele's experience. They do so by either pursuing the disclosure of his experience after his displays of resistance (extract 4) or by refocusing the talk after Samuele has engaged in a more factual report of the weekend (extract 5). These practices do not convey specific knowledge about how Samuele might have felt. They are, at most, best guesses grounded on general knowledge about Samuele (extract 4) or on what he has already made available in the meeting (extract 5).

Downgraded claims of pre-existing knowledge 
Pino - Epistemic Struggles in Addiction Therapeutic Community Meetings

The following extract is a continuation of extract 5. Marzio's turn at the end of extract 5 is reproduced at the beginning of extract 6 for convenience.

\section{Extract $6(\mathrm{Pg} 3 \mathrm{~B}: 365)$}

\begin{tabular}{|c|c|c|}
\hline & Mar & $\begin{array}{l}\text { Ma ieri è stata la giornata } \\
\text { But yesterday it was the hardest }\end{array}$ \\
\hline 02 & & $\begin{array}{l}\text { più dura dicevi comunque. } \\
\text { day you said anyway. }\end{array}$ \\
\hline 03 & & $(1.2)$ \\
\hline 04 & Sam & $\begin{array}{l}\text { tch Sì (.) non è stata una } \\
\text { tch Yes (.) it was not a }\end{array}$ \\
\hline 05 & & $\begin{array}{l}\text { giornata dura. } \\
\text { hard day. }\end{array}$ \\
\hline 06 & & $(1.0)$ \\
\hline 07 & & $\begin{array}{l}\text { Noioso? } \\
\text { Boring? }\end{array}$ \\
\hline 08 & & $(1.6)$ \\
\hline 09 & Mar & $\begin{array}{l}\text { No (.) mi sembrava: di } \\
\text { No (.) I think I }\end{array}$ \\
\hline 10 & & $\begin{array}{l}\text { capire che dal diario } \\
\text { understood from the diary }\end{array}$ \\
\hline 11 & & $\begin{array}{l}\text { era stata un po' più } \\
\text { it was a little more }\end{array}$ \\
\hline 12 & & $\begin{array}{l}\text { pesa: nte ieri rispetto a } \\
\text { hea }: \text { vy yesterday compared to }\end{array}$ \\
\hline 13 & & $\begin{array}{l}\text { venerdi. } \\
\text { Friday. }\end{array}$ \\
\hline 14 & & $(0.4)$ \\
\hline 15 & & $\begin{array}{l}\text { Quello che dicevi tu prima. } \\
\text { What you said before. }\end{array}$ \\
\hline 16 & & $(0.7)$ \\
\hline 17 & & $\begin{array}{ll}\text { Pensieri (.) } & 0 \\
\text { Thoughts } & (.) \text { or }\end{array}$ \\
\hline 18 & & $\begin{array}{l}(1.5) \text { altre cose } \\
(1.5) \text { other things }\end{array}$ \\
\hline 19 & & $\begin{array}{l}(\text { non so) } \\
(I \text { don't know) }\end{array}$ \\
\hline 20 & & $(0.8)$ \\
\hline 21 & Sam & $\begin{array}{l}\text { Sì: verso sera, (eran) } \\
\text { Yes: in the evening, (they were) }\end{array}$ \\
\hline
\end{tabular}


Samuele's answer rejects Marzio's interpretation of his earlier talk: Sunday was not a "hard" day, it was "boring" (line 7). It is also resistant, insofar as it avoids providing more than minimal access to Samuele's inner experience. Marzio's subsequent turn pursues Samuele's alignment in a post-expansion environment (Schegloff 2007). The first component of this turn (lines 9-13) embeds a stronger claim of knowledge, insofar as it invokes pre-existing and independent (although, of course, mediated) access to Samuele's experience (Heritage and Raymond 2012). As a matter of fact, Marzio mentions a diary (line 10), which the clients are required to write on a daily basis. The delayed production and the design of this "my side" telling testify to its dispreferred quality. Marzio uses a double evidential ("I think I understood", lines 9-10) and qualifies his description of Samuele's affective experience ("a little more", line 11). Following gaps in which Samuele's response is not forthcoming, Marzio expands his turn, first by again invoking what Samuele said earlier in the meeting (line 15), then by producing a bid to continue the description of the experience, in the form of a syntactically incomplete candidate answer ("Thoughts (.) or (1.5) other things (I don't know)", lines 17-19). Samuele's response again exhibits a resistant quality, insofar as it is minimally designed. Despite being composed of two turn units, it does not add information. The generic description "considerations" displays a low level of empirical engagement in the referred-to matters and, hence, conveys Samuele's unwillingness to disclose aspects of his experience.

This example suggests a dilemma that the TC educators face when pursuing information about a client's experience. Inquiries and "my side" tellings that index a relatively unknowing epistemic stance seem to be interactionally preferred, insofar as they provide for the client to produce information on his inner state instead of producing it on his behalf. At the same time, though, these practices might fail to provide the warrant for the continuing pursuit of information regarding Samuele's experience. The claim of independently pre-existing knowledge embedded in Marzio's turn in lines 9-13 provides such a warrant. However, it also exposes Marzio to possible rejection or criticism by Samuele, for at least three reasons. First, this claim is produced in an environment already characterised by disagreement. Second, because Samuele has already rejected Marzio's previous interpretation of his affective state, this new claim can be heard as challenging the client. Third, it can be heard as intrusive with respect to the client's experience. An orientation to the disaffiliative character of his epistemic claim is embodied in its elaborated turn design and its delayed production. 
Pino - Epistemic Struggles in Addiction Therapeutic Community Meetings

\section{Upgraded claims of pre-existing knowledge}

After extract 6, the educators have further pursued talk (not shown here) about Samuele's experience in the course of the weekend. At the beginning of extract 7, Samuele declines an invitation by Annamaria to tell more on the matter.

\section{Extract 7 (Pg3B:507)}

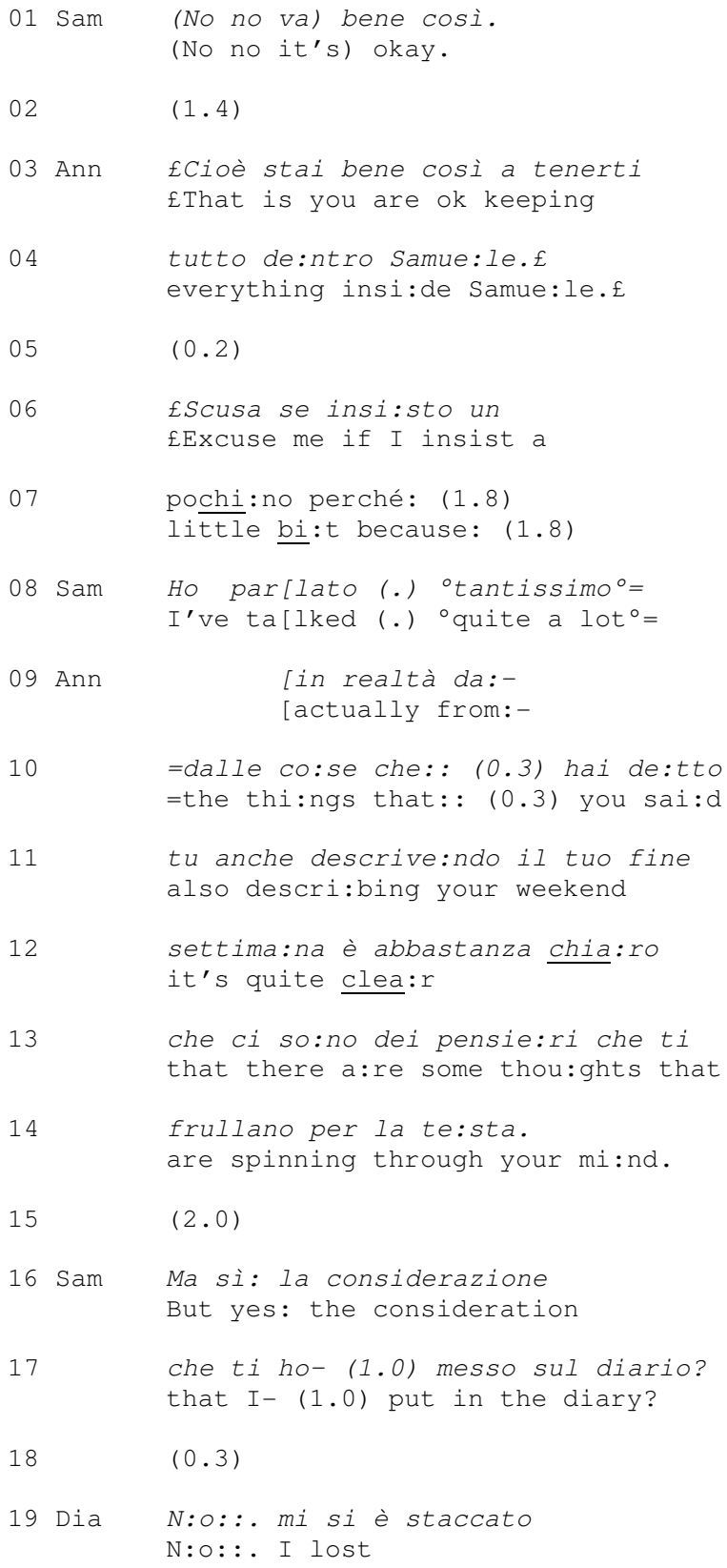




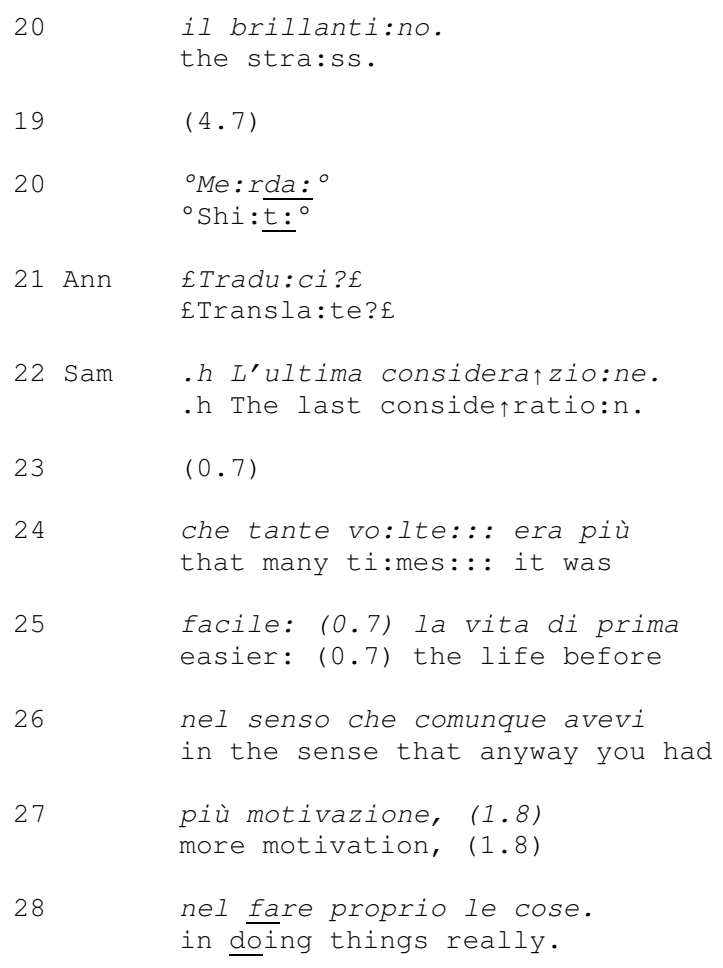

In lines 3-4 Annamaria provides an interpretation of Samuele's prior turn which challenges his claim of feeling well (Voutilainen, Peräkylä, and Ruusuvuori 2010). This "my side" telling is not designed as a dispreferred response (the only mark of dispreferredness possibly being the gap in line 2 ), however the 'smiley' quality of its vocal production mitigates its challenging character. Furthermore, its dispreferredness is acknowledged in a turn-expansion containing a meta-comment on its 'insisting' nature (lines 6-7). In line 8, Samuele resists the incitement to talk by complaining that he has already talked quite a lot. In overlap, Annamaria expands her statement, now displaying independently accessed knowledge of Samuele's inner state. Like Marzio's display of knowledge in extract 6, Annamaria's turn pursues Samuele's alignment. It achieves this import by making available an account for Annamaria's insistence, conveying that she has good reasons to be concerned about Samuele's personal state. Compared to the design of Marzio's claim of knowledge in extract 6, however, Annamaria's statement is designed to display a stronger epistemic stance. By invoking Samuele's earlier description of his own weekend (lines 9-12), Annamaria now claims that it is "quite cle:ar" that Samuele had thoughts spinning through his mind. Given the higher level of epistemic certainty with which this claim is made, it raises the pressure on Samuele and makes it harder for him to further resist the encouragement to talk.

Annamaria's claim is interpreted by Samuele as being grounded in what he wrote in his diary (lines 16-17). After Diana's (another client) 
comment (which is designed as unrelated to the exchange in progress between Annamaria and Samuele), Annamaria builds on Samuele's now provided recognition of the validity of the educator's claim. This is finally followed by a more articulated description of Samuele's experience.

\section{Discussion}

There are stakes involved in information elicitation, provision and management in TC Monday meetings. The TC educators depend on the clients to provide information regarding their activities and experiences in the previous days. At the same time, there is evidence that the TC clients can be alert to the prospective possibility of being evaluated on the basis of the information that they provide. These potentially contrasting agendas can lead to epistemic struggles in the meetings. I have considered one form that such struggles can take by analysing a case where a client withholds information. In the case examined in this study, the educators deal with a client's resistance by progressively increasing the pressure on him to provide information on his inner state in the days preceding the meeting. At the least imposing hand of the continuum, the educators display their commitment to gain knowledge of the client's experience by exhibiting a relatively unknowing epistemic stance, with no claim about how the client might have actually felt. Following the client's continued resistance, though, the educators start to claim pre-existing knowledge of his inner state. I have argued that the relative ordering of practices indexing differential states of knowledge reflect a preference for having the client provide information about his inner state. Evidence for this preference can be found in the delayed production of downgraded and upgraded knowledge claims and in the accounts and mitigations that accompany their production.

The cases examined in this article suggest that information management is a prominent part of the educators' work in Monday meetings (and possibly in other situations as well). The TC educators appear committed to obtain information about the clients' activities and mental states as part of their institutional remit. This is testified, for instance, by their use of devices (such as the diary mentioned in extracts 6 and 7) whose main purpose appears to be the gathering of information regarding the clients' activities and experiences. As a matter of fact, the TC educators are required not only to support the clients but also to monitor their behaviours (Shah, and Paget 2006). At the interface between these tasks, the TC educators can encounter practical dilemmas, one of which I have explore in this article. The practice of withholding claims of pre-existing knowledge is in accordance with a preference for having the clients report on their own experiences, but they can fail to provide the warrants for the continuing pursuit of a report of those experiences. On the other hand, claiming pre- 
existing knowledge can provide such warrants but can expose the educators to rejection and criticism.

\section{References}

Drew, Paul. 1998. "Complaints about transgressions and misconduct." Research on Language and Social Interaction 31: 295-325.

Drew, Paul, and Elizabeth Holt. 1988. "Complainable Matters: The Use of Idiomatic Expressions in Making Complaints.” Social Problems 35: 398417.

Drew, Paul. 2012. "What Drives Sequences?” Research on Language \& Social Interaction 45: 61-68.

Heritage, John. 1984. "A change-of-state token and aspects of its sequential placement." In Structures of Social Action: Studies in Conversation Analysis, ed. by J. Maxwell Atkinson, and John Heritage, 299-345. Cambridge: Cambridge University Press.

Heritage, John. 2011. "Territories of knowledge, territories of experience: empathic moments in interaction." In The Morality of Knowledge in Conversation ed. by Tanya Stivers, Lorenza Mondada, and Jakib Steensig, 159-183. Cambridge: Cambridge University Press.

Heritage, John. 2012. “The Epistemic Engine: Sequence Organization and Territories of Knowledge." Research on Language \& Social Interaction 45: 30-52.

Heritage, John, and Geoffrey Raymond. 2012. "Navigating Epistemic Landscapes: Acquiescence, Agency and Resistance in Responses to Polar Questions." In Questions: Formal, functional and interactional perspectives, ed. by Jan P. de Ruiter, 179-192. Cambridge: Cambridge University Press.

Koshik, Irene. 2010. "Questions That Convey Information in TeacherStudent Conferences." In "Why Do You Ask?" The Function of Questions in Institutional Discourse, ed. by Alice F. Freed, and Susan Erlich, 159186. Oxford: Oxford University Press.

Macpherson, R., T. R. Edwards, R. Chilvers, C. David, and H. J. Elliott. 2009. "Twenty-four hour care for schizophrenia (Review)." Cochrane Database of Systematic Reviews, Issue 2.

Mandelbaum, Jenny. 1991/1992. "Conversational Non Cooperation: An Exploration of Disattended Complaints." Research on Language \& Social Interaction 25: 97-138.

Peräkylä, Anssi, and David Silverman. 1991. "Owning Experience: Describing the Experience of Other Persons." Text 11: 441-480.

Pomerantz, Anita. 1980. "Telling My Side: "Limited Access" as a "Fishing" Device.” Sociological Inquiry: 3-4, 186-198. 
Pino - Epistemic Struggles in Addiction Therapeutic Community Meetings

Robinson, Jeffrey D., Galina B. Bolden. 2010. "Preference organization of sequence-initiating actions: The case of explicit account solicitations." Discourse Studies 12: 501-533.

Sacks, Harvey. 1987. "On the preference for agreement and contiguity in sequences in conversation." In Talk and social organization, ed. by Graham Button, and John R. E. Lee, 54-69. Clevedon: Multilingual Matters.

Schegloff, Emanuel A. 2000. "Overlapping Talk and the Organization of Turn-Making for Conversation." Language in Society, 29: 1-63.

Schegloff, Emanuel A. 2007. Sequence Organization in Interaction: A Primer in Conversation Analysis I. Cambridge: Cambridge University Press.

Shah, Deepa, and Sarah Paget. 2006. Service Standards for Addiction Therapeutic Communities (1st edition). London: The Royal College Psychiatrists'.

Sidnell, Jack. 2010. Conversation Analysis: An Introduction. Malden, MA: Wiley-Blackwell.

Voutilainen, Liisa, Anssi Peräkylä, \& Johanna Ruusuvuori, 2010. "Recognition and Interpretation: Responding to Emotional Experience in Psychotherapy." Research on Language and Social Interaction, 43: 85107. 